\title{
Clinicopathologic significance and prognostic value of Ki-67 expression in patients with gastric cancer: a meta-analysis
}

\author{
Guanying Luo ${ }^{1,2, *}$, Yunzhao Hu${ }^{1,2, *}$, Zhiqiao Zhang ${ }^{1,2}$, Peng Wang ${ }^{1}$, Zhaowen Luo ${ }^{2}$, \\ Jinxin Lin ${ }^{2}$, Canchang Cheng ${ }^{1,2}$ and You Yang ${ }^{1,2}$ \\ ${ }^{1}$ Department of Infectious Diseases, The First People's Hospital of Shunde, Shunde, Guangdong, China \\ ${ }^{2}$ Department of Internal Medicine, The Chencun Affiliated Hospital of First People's Hospital of Shunde, Shunde, Guangdong, \\ China \\ * These authors have contributed equally to this study and were co-first authors
}

Correspondence to: Zhiqiao Zhang, email: sdgrxjbk@163.com

Keywords: gastric cancer; ki-67;meta-analysis; prognostic value

Received: August 01, $2016 \quad$ Accepted: February 06, $2017 \quad$ Published: April 20, 2017

Copyright: Luo et al. This is an open-access article distributed under the terms of the Creative Commons Attribution License 3.0 (CC BY 3.0 ), which permits unrestricted use, distribution, and reproduction in any medium, provided the original author and source are credited.

\section{ABSTRACT}

Background: The prognostic value and clinicopathologic significance of Ki-67 expression in gastric cancer patients was controversial. This metaanalysis was performed to clarify the prognostic value and clinicopathologic significance of $\mathrm{Ki}-67$ expression in gastric cancer patients.

Materials and Methods: Several electronic databases were searched for eligible studies. The pooled odds ratio (OR), hazard ratios (HR) and $95 \%$ confidence interval(CI) were calculated to explore the prognostic value and clinicopathologic significance of Ki-67 expression for disease free survival and overall survival.

Results: Totally 5600 gastric cancer patients from 29 studies were included in this study. High Ki-67 expression was significantly related with Lauren's classification (OR $=1.70 ; P=0.001 ; 95 \% \mathrm{CI}$ : $1.40-2.06$ ) and tumor size(OR = 1.54; $P=0.006 ; 95 \% C I$ : 1.14-2.09). However, high Ki-67 expression was not significantly associated with lymph node metastasis (OR $=1.37 ; P=0.138 ; 95 \%$ CI: 0.90-2.08), tumor stage $(O R=1.31 ; P=0.296$; 95\% CI: 0.79-2.16) and tumor differentiation (OR $=1.03 ; P=0.839 ; 95 \%$ CI: 0.78-1.35). The pooled HRs were $1.87(P=0.001 ; 95 \%$ CI 1.30-2.69) for disease free survival and $1.23(P=0.005 ; 95 \% \mathrm{CI} 1.06-1.42)$ for overall survival.

Conclusions: High Ki-67 expression may serve as a predictive biomarker for poor prognosis in gastric cancer patients. Stratification by Ki-67 expression may be a consideration for selection of therapeutic regimen and integrated managements.

\section{INTRODUCTION}

Gastric cancer (GC) is the fourth malignant tumor and the second leading cause of tumor related death in the world [1]. Patients with advanced GC has only a median overall survival (OS) of less than 12 months [2-3]. Therefore, there is an urgent need for reliable prognostic factors to predict poor prognosis and to subdivide different risk stratification for management of GC patients.
$\mathrm{Ki}-67$ is a nuclear protein which expresses throughout the cell cycle in proliferating cells [4]. The correlation between $\mathrm{Ki}-67$ expression and prognosis of GC patients were still contradictory [5-33]. Meanwhile, the clinicopathologic significance of Ki-67 expression in GC patients was uncertain. Therefore, we performed this meta-analysis to determine the clinicopathologic significance and prognostic value of $\mathrm{Ki}-67$ expression in GC patients. 
Table 1: Characteristics of studies included in the meta analysis.

\begin{tabular}{|c|c|c|c|c|c|c|c|c|c|c|}
\hline Study & Type & Method & Cell & \begin{tabular}{|l|}
$\begin{array}{l}\text { Cutoff } \\
\text { point }\end{array}$ \\
\end{tabular} & Number & HR & \begin{tabular}{|l|}
$95 \% C I$ \\
Lower \\
\end{tabular} & \begin{tabular}{|l|}
$\begin{array}{l}95 \% \mathrm{CI} \\
\text { upper }\end{array}$ \\
\end{tabular} & $\begin{array}{ll}P \\
\text { value }\end{array}$ & \begin{tabular}{|l|} 
NOS \\
score
\end{tabular} \\
\hline Muller et al 1996[5] & $\mathrm{GC}$ & WTS & 1000 & $53.30 \%$ & 418 & 1.04 & 0.8 & 1.33 & 0.77 & 8 \\
\hline Victorzon et al 1996[6] & $\mathrm{GC}$ & WTS & 1000 & $30 \%$ & 237 & 1.1 & 0.78 & 1.55 & 0.587 & 8 \\
\hline Ohtani et al 1998[7] & $\mathrm{GC}$ & WTS & NR & $35.90 \%$ & 225 & 1.307 & 0.777 & 2.199 & 0.313 & 8 \\
\hline Manzoni et al 1998[8] & $\mathrm{GC}$ & WTS & 1000 & $10 \%$ & 56 & NR & NR & NR & $\mathrm{NR}$ & 7 \\
\hline Ikeguchi et al 1999[9] & $\mathrm{GC}$ & WTS & 1000 & $18 \%$ & 97 & 1.023 & 0.994 & 1.055 & 0.121 & 8 \\
\hline Liu et al 2001[10] & $\mathrm{GC}$ & WTS & 1000 & $27 \%$ & 190 & $\mathrm{NR}$ & $\mathrm{NR}$ & $\mathrm{NR}$ & $\mathrm{NR}$ & 7 \\
\hline $\begin{array}{l}\text { Al-Moundhri et } \quad \text { al } \\
2005[11]\end{array}$ & GC & WTS & 1000 & $25 \%$ & 121 & NR & NR & NR & NR & 7 \\
\hline Takahashi et al 2006[12] & $\mathrm{GC}$ & WTS & 1000 & $50 \%$ & 122 & 0.99 & 0.48 & 2.05 & 0.978 & 8 \\
\hline Takahashi et al 2009[13] & $\mathrm{GC}$ & WTS & 1000 & $25 \%$ & 71 & 1.25 & 0.55 & 2.86 & 0.594 & 8 \\
\hline Tsamandas et al 2009[14] & $\mathrm{GC}$ & WTS & NR & $5 \%$ & 110 & 2.93 & 1.69 & 5.08 & 0.001 & 8 \\
\hline Tzanakis et al 2009[15] & $\mathrm{GC}$ & WTS & NR & $35 \%$ & 93 & 1.48 & 0.86 & 2.54 & 0.157 & 7 \\
\hline Li et al 2009[16] & $\mathrm{GC}$ & WTS & 1000 & $10 \%$ & 336 & 2.55 & 1.8 & 3.62 & 0.001 & 8 \\
\hline Lazar et al 2010[17] & $\mathrm{GC}$ & WTS & 500 & $45 \%$ & 61 & 1.07 & 0.62 & 1.84 & 0.808 & 8 \\
\hline Lee et al 2010[18] & $\mathrm{GC}$ & WTS & 300 & $10 \%$ & 245 & 0.561 & 0.38 & 0.83 & 0.004 & 8 \\
\hline Zhao et al 2010[19] & $\mathrm{GC}$ & WTS & 1000 & $50 \%$ & 336 & NR & NR & NR & NR & 7 \\
\hline Ichinoe et al 2011[20] & $\mathrm{GC}$ & WTS & 1000 & $40 \%$ & 87 & 0.907 & 0.532 & 1.547 & 0.720 & 8 \\
\hline Nakashima et al 2011[21] & Adenocarcinoma & WTS & 1000 & $48.10 \%$ & 100 & NR & NR & NR & NR & 7 \\
\hline Wen et al 2011[22] & $\mathrm{GC}$ & TMAS & 1000 & $10 \%$ & 264 & 2.56 & 1.39 & 5.62 & 0.003 & 8 \\
\hline Giaginis et al 2011[23] & $\mathrm{GC}$ & WTS & 1000 & $50 \%$ & 66 & NR & NR & NR & NR & 7 \\
\hline He et al 2012[24] & $\mathrm{GC}$ & TMAS & 1000 & $25 \%$ & 166 & 1.85 & 1.3 & 2.63 & 0.001 & 8 \\
\hline Kang et al 2013[25] & $\mathrm{GC}$ & WTS & NR & $10 \%$ & 458 & 0.63 & 0.37 & 1.08 & 0.089 & 8 \\
\hline Liu et al 2013[26] & $\mathrm{GC}$ & WTS & $\mathrm{NR}$ & $50 \%$ & 180 & 3.44 & 1.7 & 6.96 & 0.001 & 8 \\
\hline Xiao et al 2013[27] & $\mathrm{GC}$ & TMAS & 500 & $1 \%$ & 43 & 1.32 & 0.91 & 1.9 & 0.143 & 8 \\
\hline Yang et al 2014[28] & Adenocarcinoma & WTS & 1000 & $30 \%$ & 159 & 1.13 & 0.63 & 2.05 & 0.682 & 8 \\
\hline Ayed et al 2014[29] & $\mathrm{GC}$ & WTS & 1000 & $1 \%$ & 90 & NR & NR & NR & NR & 7 \\
\hline Li et al 2015[30] & $\mathrm{GC}$ & WTS & NR & $50 \%$ & 69 & 1.5 & 0.59 & 3.71 & 0.394 & 8 \\
\hline Boger et al 2016[31] & $\mathrm{GC}$ & WTS & 500 & $50 \%$ & 315 & 1.08 & 0.88 & 1.33 & 0.461 & 7 \\
\hline Huang et al 2016[32] & Adenocarcinoma & WTS & NR & $50 \%$ & 693 & 1.421 & 1.191 & 1.695 & 0.001 & 8 \\
\hline Ou et al 2016[33] & Adenocarcinoma & TMAS & NR & $5 \%$ & 192 & 1.1 & 0.9 & 1.35 & 0.352 & 8 \\
\hline
\end{tabular}

HR , hazard ratio; CI , confidence interval; NOS, Newcastle-Ottawa Quality Assessment Scale.

\section{RESULTS}

\section{Search results}

The initial search returned 595 articles (with 75 duplicate articles). After screening the abstracts, 445 irrelevant articles were excluded. Reviewers identified 75 potential studies for full-text review and 46 articles were eliminated due to inadequate data. Finally, 29 studies were included in the present study [5-33]. The details of screening process were shown in Figure 1.

\section{Study selection and characteristics}

The characteristic of included studies were summarized in Table 1. The publication time of included studies was between 1996 and 2016.The study sample size was between 56 and 693 , with a mean sample size of 193. The NOS score of 29 studies varied from 7 to 8 , with a mean value of 7.73 . Twenty-three studies provided survival information and fifteen studies presented clinicopathologic parameters.

\section{Association of $\mathrm{Ki}-67$ expression with clinicopathologic parameters}

As shown in Figure 2, high Ki-67 expression was significantly related with Lauren's classification $(\mathrm{OR}=$ $1.70 ; P=0.001 ; 95 \%$ CI: $1.40-2.06)$ and tumor size(OR $=1.54 ; P=0.006 ; 95 \% \mathrm{CI}: 1.14-2.09)$. However, high Ki67 expression was not significantly associated with lymph node metastasis $(\mathrm{OR}=1.37 ; P=0.138 ; 95 \% \mathrm{CI}$ : 0.90 $2.08)$, tumor stage $(\mathrm{OR}=1.31 ; P=0.296$; $95 \% \mathrm{CI}$ : 0.79 - 
2.16) and tumor differentiation ( $\mathrm{OR}=1.03 ; P=0.839$; 95\% CI: 0.78-1.35).

\section{Prognostic value of high Ki-67 expression in gastric cancer patients}

A total of $4741 \mathrm{GC}$ patients from 23 eligible studies were included and analyzed for prognostic value of $\mathrm{Ki}$ 67 expression in GC patients(Figure 3 and Figure 4). The pooled HRs was $1.87(P=0.001 ; 95 \%$ CI $1.30-2.69)$ for DFS and $1.23(P=0.005 ; 95 \%$ CI $1.06-1.42)$ for OS.

\section{Sensitivity analysis}

All studies were sequentially removed to explore that whether any individual study had an significant influence to the pooled HR. The pooled HR in sensitivity meta-analysis ranged from $1.17(95 \% \mathrm{CI}: 1.02-1.34)$ to 1.28 (95\%CI: 1.11-1.48) for OS, demonstrating that the pooled HR was not significantly affected by any individual study(Table 2).

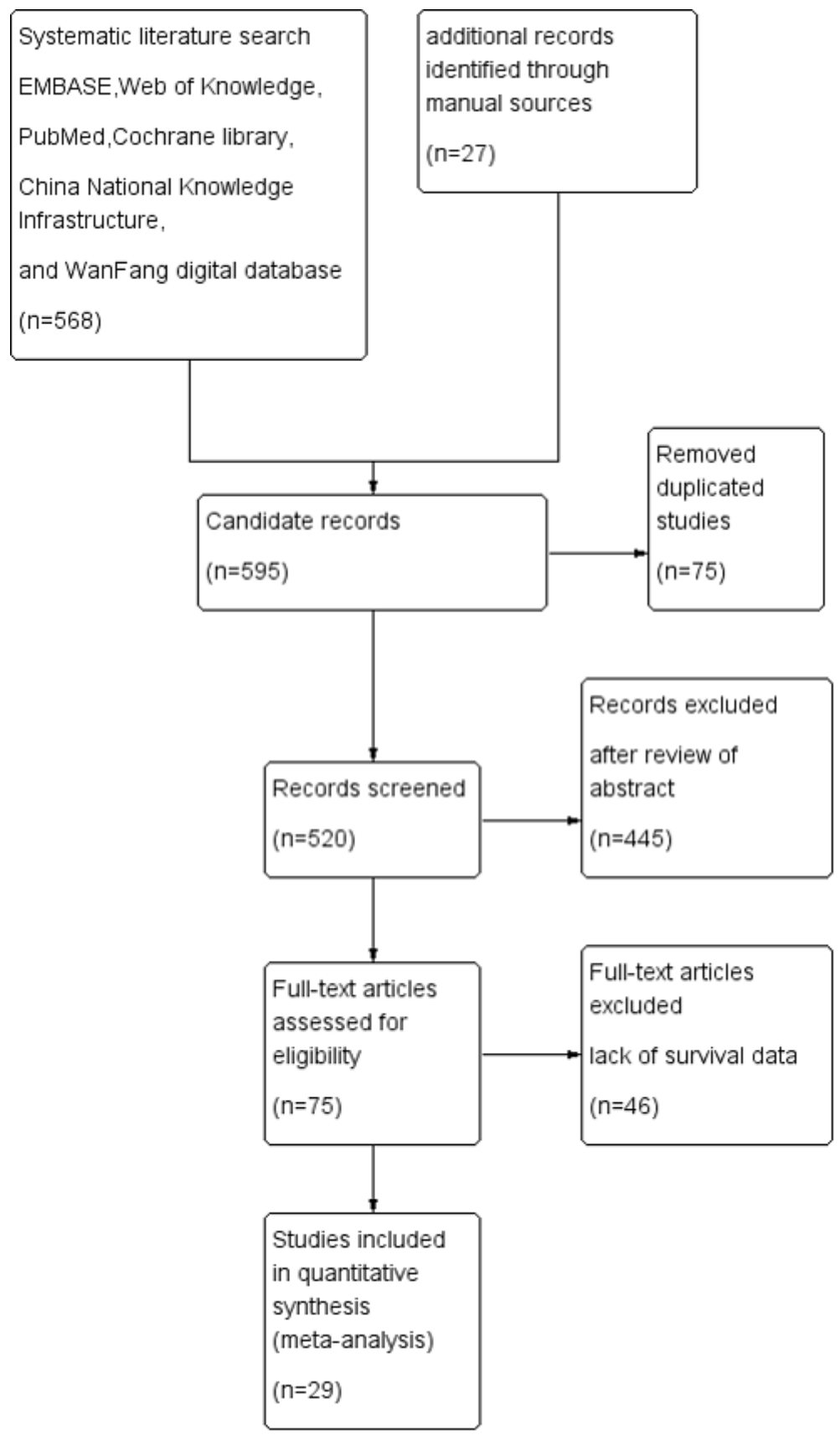

Figure 1: Flowchart of study selection in present meta-analysis. 
Table 2: Effect of individual studies on the pooled HRs of Ki-67 expression for overall survival.

\begin{tabular}{|l|l|l|l|}
\hline Study omitted & Estimate HR & $\mathbf{9 5}$.CI & Upper \\
\hline & & Lower & 1.4572761 \\
\hline 1 & 1.2472792 & 1.0675433 & 1.4449806 \\
\hline 3 & 1.240342 & 1.0646844 & 1.4268255 \\
\hline 4 & 1.2284332 & 1.0576263 & 1.5096903 \\
\hline 5 & 1.2592941 & 1.0504285 & 1.4425511 \\
\hline 6 & 1.243209 & 1.0714135 & 1.4273434 \\
\hline 7 & 1.2308739 & 1.0614478 & 1.3689484 \\
\hline 8 & 1.1883517 & 1.03158 & 1.4186638 \\
\hline 9 & 1.2223002 & 1.0531162 & 1.3445334 \\
\hline 10 & 1.1733439 & 1.0239507 & 1.4386851 \\
\hline 11 & 1.238404 & 1.0660043 & 1.4825042 \\
\hline 12 & 1.2813864 & 1.1075524 & 1.4644465 \\
\hline 13 & 1.2639937 & 1.0909787 & 1.3923169 \\
\hline 14 & 1.2044084 & 1.0418602 & 1.3901081 \\
\hline 15 & 1.2009488 & 1.0375293 & 1.4652347 \\
\hline 16 & 1.2637651 & 1.0899976 & 1.376326 \\
\hline 17 & 1.1940765 & 1.0359601 & 1.4274106 \\
\hline 18 & 1.2269805 & 1.0546938 & 1.4344743 \\
\hline 19 & 1.2353078 & 1.063794 & 1.4213671 \\
\hline 20 & 1.2264266 & 1.0582221 & 1.4599268 \\
\hline 21 & 1.2459158 & 1.0632767 & 1.4219306 \\
\hline 22 & 1.2191019 & 1.0452053 & 1.4765527 \\
\hline Combined HR & 1.2612625 & 1.0773629 & 1.4237409 \\
\hline & 1.2309021 & 1.0641824 & \\
\hline
\end{tabular}

HR , hazard ratio; CI , confidence interval.

Table 3: Subgroup analyses for associations between Ki-67 expression and overall survival in gastric cancer patients.

\begin{tabular}{|l|l|l|l|l|l|l|l|l|}
\hline & & \multicolumn{3}{|l|}{ Overall survival } & \multicolumn{2}{l|}{ 95\%CI } & \multicolumn{2}{l|}{ Heterogeneity } \\
\hline Group factors & Subgroup & Study & HR & P value & Lower & Upper & $\boldsymbol{I}^{2}$ & $\boldsymbol{P}$ value \\
\hline Total & Total & 22 & 1.23 & 0.005 & 1.06 & 1.42 & $79.7 \%$ & 0.001 \\
\hline patients $\geq 100$ & Yes & 15 & 1.31 & 0.017 & 1.05 & 1.62 & $82.7 \%$ & 0.001 \\
\hline & No & 7 & 1.08 & 0.386 & 0.91 & 1.28 & $26.3 \%$ & 0.228 \\
\hline Adenocarcinoma & Yes & 3 & 1.14 & 0.476 & 0.80 & 1.62 & $81.3 \%$ & 0.005 \\
\hline & No & 19 & 1.26 & 0.01 & 1.06 & 1.50 & $80.0 \%$ & 0.001 \\
\hline THAS & Yes & 3 & 1.45 & 0.096 & 0.94 & 2.25 & $83.1 \%$ & 0.001 \\
\hline & No & 19 & 1.19 & 0.037 & 1.01 & 1.41 & $79.7 \%$ & 0.001 \\
\hline Cell number=1000 & Yes & 10 & 1.27 & 0.057 & 0.99 & 1.62 & $81.0 \%$ & 0.001 \\
\hline & No & 4 & 0.97 & 0.847 & 0.69 & 1.36 & $73.2 \%$ & 0.011 \\
\hline Cut-off point $\geq 25 \%$ & Yes & 14 & 1.24 & 0.01 & 1.05 & 1.46 & $53.0 \%$ & 0.01 \\
\hline & No & 8 & 1.24 & 0.143 & 0.93 & 1.66 & $88.8 \%$ & 0.001 \\
\hline
\end{tabular}

HR ,hazard ratio; CI , confidence interval.

\section{Publication bias}

The figure of Begg's funnel plot (Figure 5) did not show any evidence of asymmetry for OS $(P=0.499)$. Similarly, there were no evidences for publication bias in terms of Lauren's classification $(P=0.721)$, tumor $\operatorname{size}(P$
$=0.881)$, lymph node metastasis $(P=0.788)$, tumor stage $(P=1.0)$ and tumor differentiation $(P=0.734)$. The further Egger's linear regression test did not find any significant evidences of publication bias for Lauren's classification $(P$ $=0.435)$, tumor size $(P=0.586)$, lymph node metastasis $(P$ $=0.750)$, tumor stage $(P=0.627)$, tumor differentiation $(P=0.652)$ and $\operatorname{OS}(P=0.066)$. 
Stability assessment of the pooled hazard ratios of Ki-67 expression for overall survival by cumulative meta-analysis

The pooled HRs of cumulative meta-analysis(Figure 6) ranged from $1.23(95 \% \mathrm{CI}: 1.06-1.42)$ to $1.27(95 \% \mathrm{CI}$ : 1.04-1.56) for OS since 2013, demonstrating that performance of Ki-67 expression for OS in GC patients was stable and reliable.
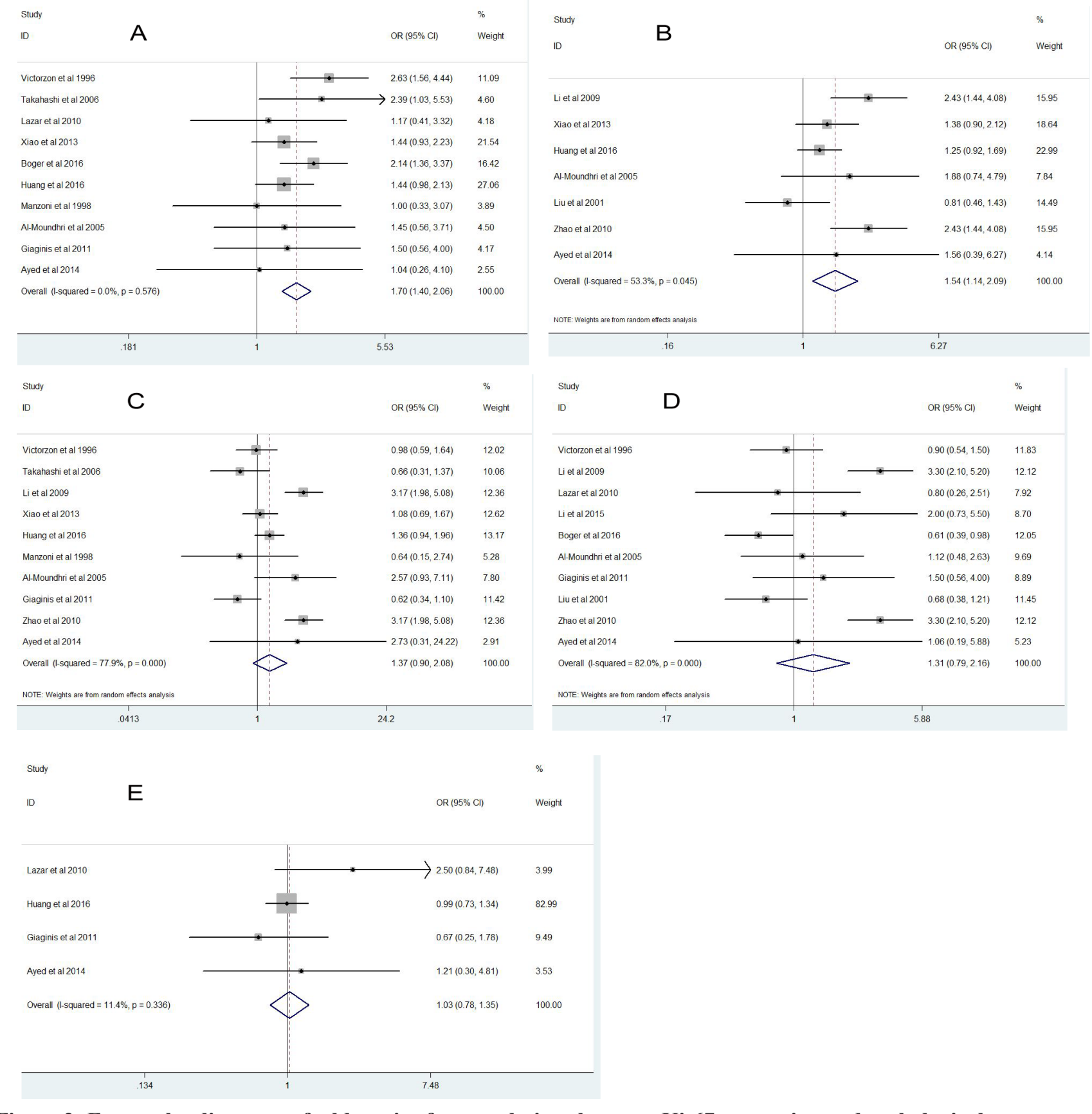

Figure 2: Forest plot diagrams of odds ratios for correlations between Ki-67 expression and pathological parameters.

\section{Explore of sources of heterogeneity by meta- regression analyses and subgroup analyses}

The pooled HR was $1.31(95 \%$ CI $1.05-1.62 ; P$ $=0.017$; heterogeneity $=82.7 \% ; P<0.001)$ in studies with patient number more than 100 for OS whereas it was $1.08(95 \%$ CI $0.91-1.28 ; P=0.386$; heterogeneity $=$ $26.3 \% ; P<0.228)$ in studies with patient number not more than 100 (Table 3). The results suggested that sample size might contributed to the clinical heterogeneity. However, meta-regression analysis did not find any source of heterogeneity (all $P>0.05$, data not shown). 


\section{DISCUSSION}

The current meta analysis showed that high Ki67 expression was significantly related with Lauren's classification $(\mathrm{OR}=1.70 ; 95 \% \mathrm{CI}: 1.40-2.06)$ and tumor size $(\mathrm{OR}=1.54 ; 95 \% \mathrm{CI}: 1.14-2.09)$. The pooled HRs were $1.87(95 \%$ CI $1.30-2.69)$ for DFS and $1.23(95 \%$ CI 1.06-1.42) for OS. These results demonstrated that high $\mathrm{Ki}-67$ expression significantly predicts poorer prognosis compared with low Ki-67 expression.

Some previous studies have reported that high Ki-67 expression was associated with poor OS in GC patients $[14,16,22,24,26,32]$. These original studies have revealed that high $\mathrm{Ki}-67$ expression had a predictive value for prognosis of GC patients. Our conclusion was consistent with that of these previous studies. Recently, several meta analyses have reported that high $\mathrm{Ki}$ -
67 expression was associated with poor prognosis in different tumors, including gastrointestinal stromal tumor, cervical cancer and non-small cell lung cancer [35-37]. Furthermore, two studies have further reported that Ki-67 expression could be used for risk stratification in patients with gastrointestinal stromal tumor [38-39].

The heterogeneity was significant in the present meta-analysis. There might be some potential sources of heterogeneity as follows: First, the heterogeneity caused by different cut-off values of Ki-67 expression was inevitable. Second, subgroup analyses showed that sample size might be a potential source of heterogeneity. Third, the identify methods of Ki-67 expression (TMAS or WTS) and the number of count cells(1000 or 500) might yield variation in different studies. In addition, heterogeneity could be caused by other factors, such as study regions, pathology types, tumor stages, treatments and races.

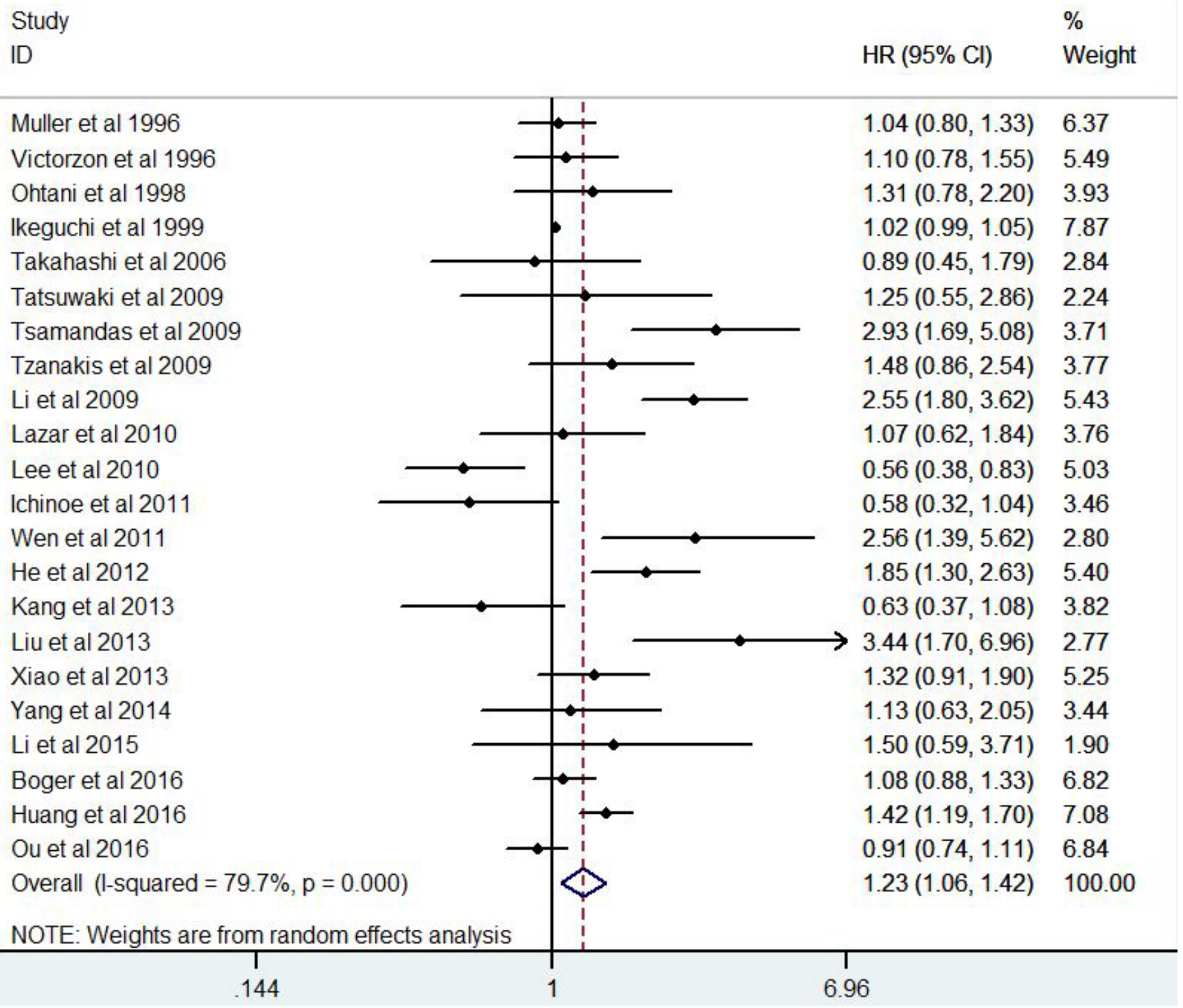

Figure 3: Forest plot diagrams of hazard ratios for correlations between Ki-67 expression and overall survival. 
Although significant heterogeneity existed in the present meta-analysis, sensitivity analyses and cumulative meta-analyses demonstrated that HRs of Ki-67 expression for prognosis of GC patients was stable and reliable. Furthermore, we performed Begg's funnel plot and
Egger's test to assess the potential publication bias and did not find any evidence of publication bias.

The present meta analysis had several strengths: Firstly, we first explored the association between $\mathrm{Ki}$ 67 expression and clinicopathologic parameters in GC

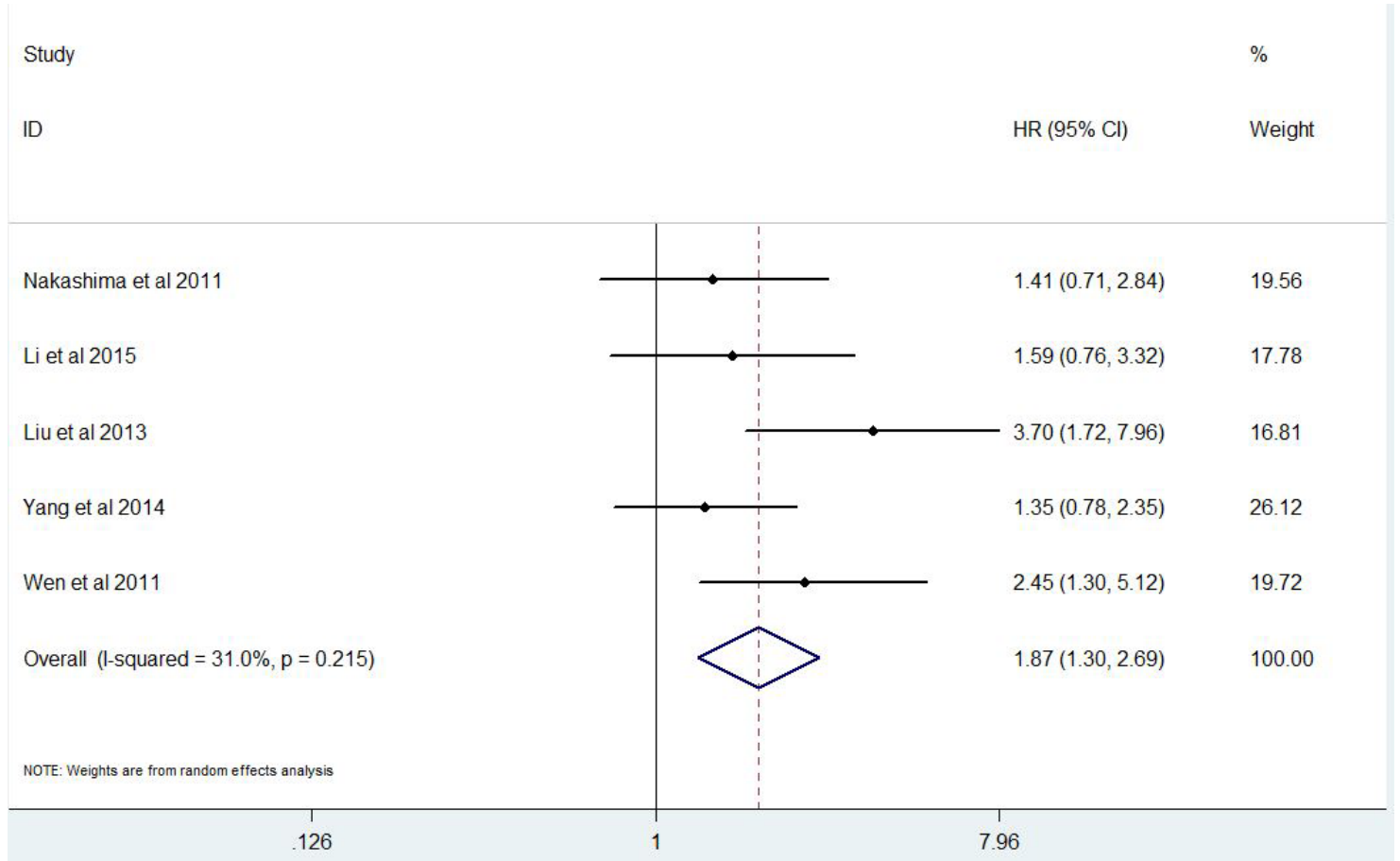

Figure 4: Forest plot diagrams of hazard ratios for correlations between Ki-67 expression and disease free survival .

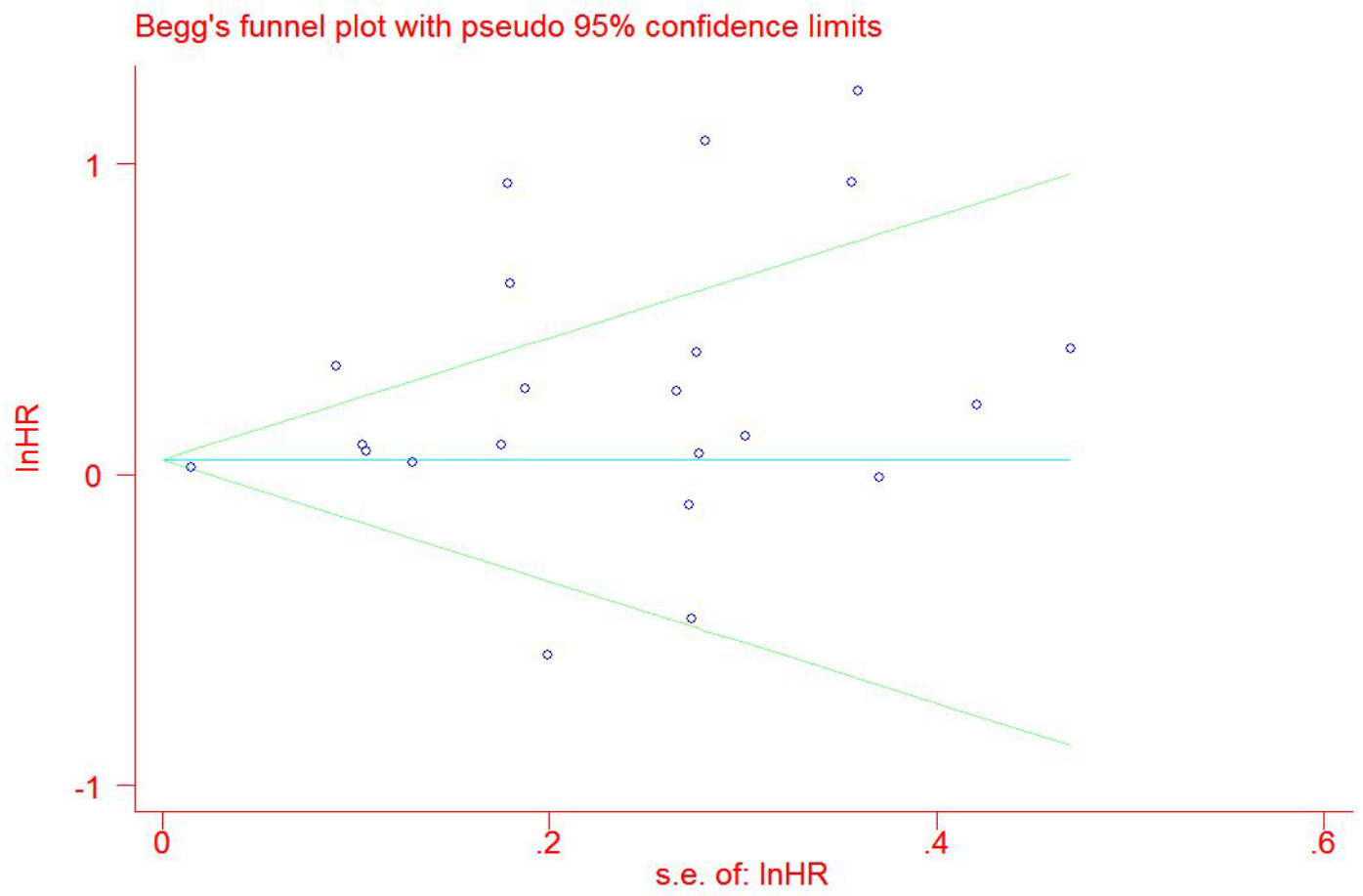

Figure 5: Begg's funnel plot for studies which provided hazard ratios of high Ki-67 expression for overall survival (P $=0.499$ ). 
patients. Secondly, we included 29 eligible studies and 5600 patients, which could strengthen persuasiveness of the conclusions. Thirdly, Ki-67 expression in 29 eligible studies was all detected by IHC. Fourthly, studies published in Chinese were included as English literature to increase representation of study population.

The results of the present meta analysis need to be interpreted cautiously for several limitations. First, most studies defined positive status of Ki-67 expression according to different cut-off values. Second, heterogeneity was inevitable due to different baseline characteristics. Third, although the method for extracting survival information from survival curve is widely accepted, we could not completely eliminate the sources of information inaccuracy in the process of extracting data.
In conclusion, high Ki-67 expression may serve as a predictive biomarker for poor prognosis in gastric cancer patients. Stratification by Ki-67 expression may be a consideration for selection of therapeutic regimen and integrated managements.

\section{MATERIALS AND METHODS}

\section{Search strategy}

Several electronic databases, including PubMed, EMBASE, Cochrane Library, Web of Knowledge, China National Knowledge Infrastructure and WanFang data, were searched from January 1970 to May 2016.

Study

ID

$\mathrm{ES}(95 \% \mathrm{Cl})$

Muller et al 1996

Victorzon et al 1996

Ohtani et al 1998

Ikeguchi et al 1999

Takahashi et al 2006

Tatsuwaki et al 2009

Tsamandas et al 2009

Tzanakis et al 2009

Li et al 2009

Lazar et al 2010

Lee et al 2010

Ichinoe et al 2011

Wen et al 2011

$\mathrm{He}$ et al 2012

Kang et al 2013

Liu et al 2013

Xiao et al 2013

Yang et al 2014

Li et al 2015

Boger et al 2016

Huang et al 2016

Ou et al 2016

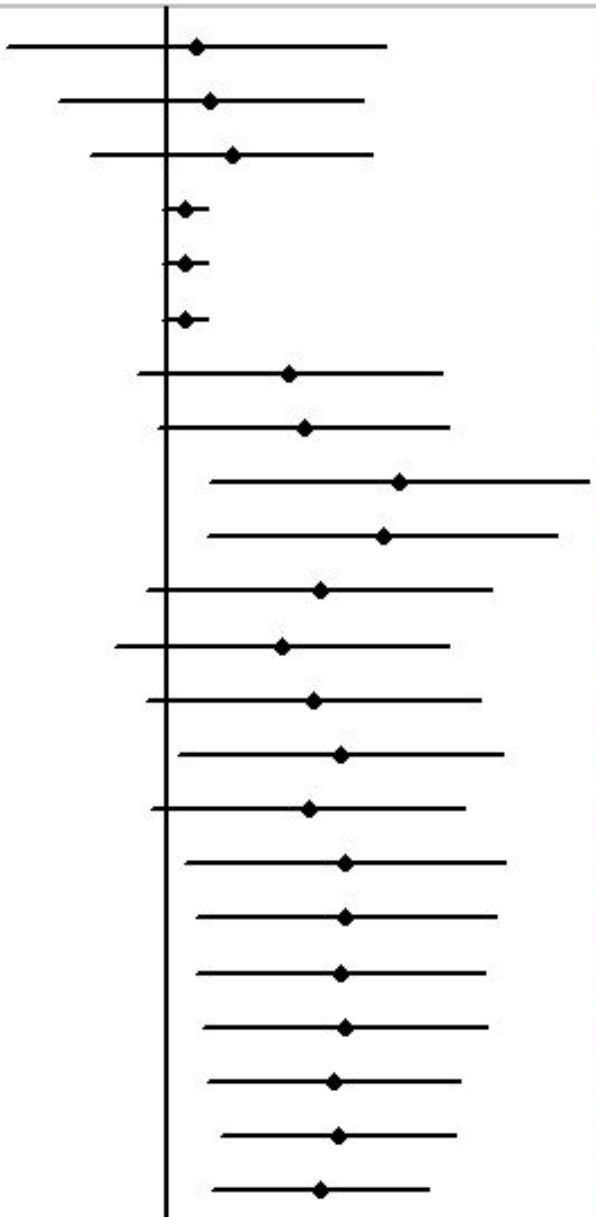

$1.04(0.81,1.34)$

$1.06(0.86,1.30)$

$1.09(0.90,1.32)$

$1.02(0.99,1.06)$

$1.02(0.99,1.05)$

$1.02(0.99,1.06)$

$1.18(0.96,1.45)$

$1.20(0.99,1.46)$

$1.37(1.06,1.77)$

$1.34(1.06,1.69)$

$1.23(0.97,1.55)$

$1.17(0.93,1.46)$

$1.22(0.97,1.53)$

$1.26(1.01,1.57)$

$1.21(0.98,1.50)$

$1.27(1.02,1.58)$

$1.27(1.04,1.56)$

$1.27(1.04,1.54)$

$1.27(1.05,1.54)$

$1.25(1.06,1.48)$

$1.26(1.08,1.48)$

$1.23(1.06,1.42)$

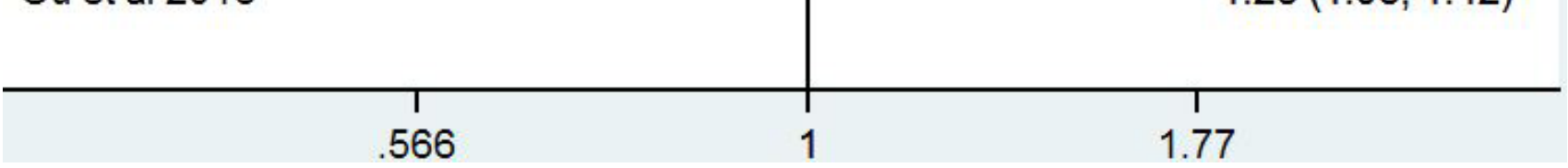

Figure 6: Cumulative meta-analysis for stability of the hazard ratios of Ki-67 for overall survival in gastric cancer patients. 
We performed literature search by combined text word and $\mathrm{MeSH}$ (Emtree for EMBASE database accordingly) strategy with terms "Ki-67 Antigen" or "MIB-1 Antigen" and "gastric cancer" or "gastric carcinoma" or "stomach tumor" and "survival" or "outcome" or "prognosis" or "prognostic". The strategy was correspondingly adjusted in different databases. In the retrieval process, expanded search of hyponym was performed. We made a manual search using the reference lists of the relevant articles. We contacted the corresponding author to get necessary information if necessary. The search was restricted to human studies, but there was no restriction on language or publication time. All clinical investigation and data achievement were conducted according to the principles expressed in the Declaration of Helsinki.

\section{Criteria for inclusion and exclusion}

The inclusion criteria were as follows: (1) proven pathological diagnosis of GC in humans; (2) Ki-67 expression evaluation using immunohistochemistry (IHC) method; (3)provided information on clinicopathological parameters and/or overall survival information. Studies not directly providing survival information were included if survival information were available from survival curve. Articles published in Chinese were included as English literature. Only the most recent study was included among duplicate studies. There were no restrictions on sample size or follow-up period.

The following studies were excluded: (1) reviews, letters, case reports, and conference abstracts without original data; (2) non-human experiments;(3) laboratory studies;(4)articles from which the necessary information could not be extracted.

\section{Quality assessment of studies}

Two reviewers (Zhiqiao Zhang and Jinxin Lin) independently assessed the quality of studies using the Newcastle-Ottawa Quality Assessment Scale(NOS) (Table 1). Disagreements were resolved through consensus with a third reviewer (Guanying Luo).

\section{Data extraction}

Two investigators (Zhiqiao Zhang and Jinxin Lin) independently extracted and examined the following data: surname of the first author, publication year, country, sample size, disease stage, detection method of Ki-67, clinical parameters and survival outcome data. Study information was extracted and recorded using a standardized form. All eligible studies were coded as surname of the first author + publish year in the standardized form. Study authors were contacted to obtain key information if necessary. When necessary, a third investigator (Guanying Luo) helped to reach a consensus.

\section{Statistical analysis}

The statistical analysis was performed according to the guidelines suggested by the Meta-Analysis of Observational Studies in Epidemiology group(MOOSE) [34]. The pooled odds ratio (OR) were combined to explore the association between KI-67 expression and clinicopathological parameters. The pooled hazard ratio (HR) were used to summary outcome of overall survival. While survival data were not directly reported, we extracted survival information from Kaplan-Meier curve. The heterogeneity among different studies was measured by the Q and $I^{2}$ tests. A probability value of $I^{2} \geq 30 \%$ and $P$ $<0.1$ indicated the existence of significant heterogeneity. A random effect model (DerSimonian and Laird method) or fixed effect model(Mantel-Haenszel method) was used depending on the results of heterogeneity analysis. The potential publication bias was assessed by Begg's funnel plot and Egger's test. $P$ value $<0.05$ was considered statistically significant. The statistical analyses were performed by STATA version 12.0 software (Stata Corporation, College Station, Texas, USA).

\section{Abbreviations}

Gastric cancer GC
odds ratio OR
hazard ratio HR
confidence interval CI.

\section{Author contribution}

Peng Wang, and Zhiqiao Zhang designed the study. Zhiqiao Zhang and Jixin Lin performed the research; Zhiqiao Zhang and Jixin Lin collected and analyzed the data; Zhiqiao Zhang and Jixin Lin wrote the paper; Yunzhao $\mathrm{Hu}$, Guanying Luo, Zhaowen Luo, and Canchang Cheng amended the article. Zhiqiao Zhang act as the submission's guarantor and takes responsibility for the integrity of the work as a whole, from inception to published article. All authors reviewed the manuscript.

\section{ACKNOWLEDGMENTS}

This study was funded in part by Health Department and Finance Department of Guangdong Province.

\section{CONFLICTS OF INTERESTS}

The authors have declared that they had no conflict of interests. 


\section{FUNDING}

This study was funded in part by Health Department and Finance Department of Guangdong Province. The Grant Numbers were No: A2013695 (Grant Recipient: Peng Wang) and No: A2016450 (Grant Recipient: Zhiqiao Zhang).The total funding account was RMB 15000.

The funders had no role in study design, data collection and analysis, decision to publish, or preparation of the manuscript.

\section{REFERENCES}

1. Ferlay J, Shin HR, Bray F, Forman D, Mathers C, Parkin M. Estimates of worldwide burden of cancer in 2008: GLOBOCAN 2008. Int J Cancer.2010;127:2893-2817.

2. Ferlay J, Soerjomataram I, Dikshit R, Eser S, Mathers C, Rebelo M, Parkin DM, Forman D, Bray F. Cancer incidence and mortality worldwide: sources, methods and major patterns in GLOBOCAN 2012. Int $\mathrm{J}$ Cancer.2015;136:359-386.

3. Cunningham D, Starling N, Rao S, Iveson T, Nicolson M, Coxon F, Middleton G, Daniel F, Oates J, Norman AR. Capecitabine and oxaliplatin for advanced esophagogastric cancer. N Engl J Med.2008;358:36-46.

4. Schluter C, Duchrow M, Wohlenberg C, Becker MH, Key G, Flad HD. The cell proliferation-associated antigen of antibody Ki-67: a very large, ubiquitous nuclear protein with numerous repeated elements,representing a new kind of cell cycle-maintaining proteins. J Cell Biol. 1993;123:513-522.

5. Muller W, Schneiders A, Meier S, Hommel G, Gabbert HE. Immunohistochemical study on the prognostic value of MIB-1 in gastric carcinoma.Br J Cancer.1996;74:759-765.

6. Victorzon M, Roberts PJ, Haglund C, von Boguslawsky K, Nordling S.Ki-67 immunoreactivity, ploidy and S-phase fraction as prognostic factors in patients with gastric carcinoma. Oncology. 1996;53:182-191.

7. Ohtani M, Isozaki H, Fujii K, Nomura E, Niki M, Mabuchi $\mathrm{H}$, Nishiguchi K, Toyoda M, Ishibashi T, Tanigawa N. Impact of the expression of cyclin-dependent kinase inhibitor p27Kip1 and apoptosis in tumor cells on the overall survival of patients with non- early stage gastric carcinoma.Cancer.1999;85:1711-1718.

8. Manzoni GD, Verlato G, Tomezzoli A, Guglielmi A, Pelosi G, Ricci F, Leo DA, Cordiano C. Study on Ki-67 immunoreactivity as a prognostic indicator in patients with advanced gastric cancer.Jpn J Clin Oncol.1998;28:534-537.

9. Ikeguchi M, Saito H, Kondo A, Tsujitani S, Maeta M, Kaibara N.Mutated p53 protein expression and proliferative activity in advanced gastric cancer. Hepatogastroenterology.1999;46:2648-2653.

10. Liu XP, Tsushimi K, Tsushimi M, Kawauchi S, Oga A, Furuya T, Sasaki K. Expression of p21(WAF1/CIP1) and p53 proteins in gastric carcinoma: its relationships with cell proliferation activity and prognosis.Cancer Lett.2001;170:183-189.

11. Al-Moundhri MS, Nirmala V, Al-Hadabi I, Al-Mawaly K, Burney I, Al-Nabhani M, Thomas V, Ganguly SS, Grant C. The prognostic significance of p53, p27 kip1, p21 waf1, HER-2/neu, and $\mathrm{Ki} 67$ proteins expression in gastric cancer: a clinicopathological and immunohistochemical study of 121 Arab patients.J Surg Oncol.2005;91:243-252.

12. Takahashi H, Murai Y, Tsuneyama K, Nomoto K, Okada E, Fujita H, Takano Y. Overexpression of phosphorylated histone $\mathrm{H} 3$ is an indicator of poor prognosis in gastric adenocarcinoma patients.Appl Immunohistochem Mol Morphol.2006;14:296-302.

13. Tatsuwaki $H$, Tanigawa $T$, Watanabe $T$, Machida $H$, Okazaki H, Yamagami H, Shiba M, Watanabe K, Tominaga K, Fujiwara Y, Oshitani N, Muguruma K, Sawada T, et al. Reduction of 15- hydroxyprostaglandin dehydrogenase expression is an independent predictor of poor survival associated with enhanced cell proliferation in gastric adenocarcinoma.Cancer Sci.2010;101:550-558.

14. Tsamandas AC, Kardamakis D, Tsiamalos P, Liava A, Tzelepi V, Vassiliou V, Petsas T, Vagenas K, Zolota V, Scopa CD. cases of gastric carcinoma and correlation with classic prognostic factors and patient outcome.Anticancer Res.2009;29:703-709.

15. Tzanakis NE, Peros G, Karakitsos P, Giannopoulos GA, Efstathiou SP, Rallis G, Tsigris C, Kostakis A, Nikiteas NI. Prognostic significance of p53 and Ki67 proteins expression in Greek gastric cancer patients.Acta Chir Belg.2009;109:606-611.

16. Li YZ, Zhao P. Expressions of cyclinB1, FHIT and Ki-67 in 336 gastric carcinoma patients and their clinicopathologic significance. Zhonghua Yi Xue Za Zhi.2009;89:23372341(Chinese).

17. Lazar D, Taban S, Sporea I, Dema A, Cornianu M, Lazar E, Goldis A, Vernic C. Ki-67 expression in gastric cancer. Results from a prospective study with long-term follow-up. Rom J Morphol Embryol.2010;51:655-661.

18. Lee HE, Kim MA, Lee BL, Kim WH. Low Ki-67 proliferation index is an indicator of poor prognosis in gastric cancer.J Surg Oncol.2010;102:201-206.

19. Zhao P, Li Y, Lu Y. Aberrant expression of CD133 protein correlates with $\mathrm{Ki}-67$ expression and is a prognostic marker in gastric adenocarcinoma.BMC Cancer.2010;10:218.

20. Ichinoe M, Mikami T, Yoshida T, Igawa I, Tsuruta T, Nakada N, Anzai N, Suzuki Y, Endou H, Okayasu I. High expression of L-type amino-acid transporter 1 (LAT1) in gastric carcinomas: comparison with non-cancerous lesions. Pathol Int.2011;61:281-289.

21. Nakashima Y, Yao T, Hirahashi M, Aishima S, Kakeji Y, Maehara Y, Tsuneyoshi M. Nuclear atypia grading score is a useful prognostic factor in papillary gastric adenocarcinoma.Histopathology.2011; 59:841-849. 
22. Wen Y, Wang Q, Zhou C, Yan D, Qiu G, Yang C, Tang H, Peng Z. Decreased expression of RASSF6 is a novel independent prognostic marker of a worse outcome in gastric cancer patients after curative surgery.Ann Surg Oncol.2011;18:3858-3867.

23. Giaginis C, Giagini A, Tsourouflis G, Gatzidou E, Agapitos E, Kouraklis G, Theocharis S. MCM-2 and MCM-5 expression in gastric adenocarcinoma: clinical significance and comparison with Ki-67 proliferative marker.Dig Dis Sci.2011;56:777-785.

24. He WL, Li YH, Yang DJ, Song W, Chen XL, Liu FK, Wang Z, Li W, Chen W, Chen CY, He YL, Zhan WH. Combined evaluation of centromere protein $\mathrm{H}$ and $\mathrm{Ki}-67$ as prognostic biomarker for patients with gastric carcinoma.Eur J Surg Oncol.2013;39:141-149.

25. Kang Y, Jung WY, Lee H, Jung W, Lee E, Shin BK, Kim A, Kim HK, Kim BH. Prognostic significance of heat shock protein 70 expression in early gastric carcinoma.Korean J Pathol.2013;47:219-26.

26. Liu M, Li JS, Tian DP, Huang B, Rosqvist S, Su M.CM2 expression levels predict diagnosis and prognosis in gastric cardiac cancer.Histol Histopathol.2013;28:481-492.

27. Xiao LJ, Zhao S, Zhao EH, Zheng X, Gou WF, Takano Y. Clinicopathological and prognostic significance of Ki-67, caspase-3 and p53 expression in gastric carcinomas. Oncol Lett.2013;6:1277-1284.

28. Yang M, Wang X, Zhao Q, Liu T, Yao G, Chen W, Li Z, Huang X, Zhang Y. Combined evaluation of the expression of NUCKS and Ki-67 proteins as independent prognostic factors for patients with gastric adenocarcinoma.Tumour Biol.2014;35:7505-7512.

29. Ayed DB, Khabir A, Abid M, Bayrouti MI, Gargouri A, Sellami-Boudawara T, Mokdad-Gargouri R. Clinicopathological and prognostic significance of p53, Ki-67, and Bcl-2 expression in Tunisian gastric adenocarcinomas.Acta Histochem.2014;116:1244-1250.

30. Li N, Deng W, Ma J, Wei B, Guo K, Shen W, Zhang Y, Luo S. Prognostic evaluation of Nanog, Oct4, Sox2, PCNA, Ki67 and E- cadherin expression in gastric cancer.Med Oncol.2015;32:433.

31. Boger C, Behrens HM, Rocken C.Ki67--An unsuitable marker of gastric cancer prognosis unmasks intratumoral heterogeneity.J Surg Oncol.2016;113:46-54.
32. Huang G, Chen S, Wang D, Wang R, Lin L, Chen S, Wang L, Huang Q. High Ki67 Expression has Prognostic Value in Surgically-Resected T3 Gastric Adenocarcinoma.Clin Lab.2016;62:141-153.

33. Ou Y, Xia R, Kong F, Zhang X, Yu S, Jiang L. Overexpression of DEK is an indicator of poor prognosis in patients with gastric adenocarcinoma.Oncol Lett.2016;11:1823-1828.

34. Stroup DF, Berlin JA, Morton SC, Williamson GD, Rennie D, Moher D, Moher D, Becker BJ, Sipe TA, Thacker SB. Meta-analysis of observational studies in epidemiology: a proposal for reporting. Metaanalysis Of Observational Studies in Epidemiology (MOOSE) group.JAMA. 2000;283:2008-2012.

35. Pyo JS,Kang G, Sohn JH. Ki-67labeling index can be used as a prognostic marker in gastrointestinal stromal tumor: asystematic review and meta-analysis.Int J Biol Markers.2016;31:e204-210.

36. Pan D, Wei K, Ling Y, Su S, Zhu M, Chen G. The prognostic role of $\mathrm{Ki}-67 / \mathrm{MIB}-1$ in cervical cancer: a systematic review with meta-analysis.Med Sci Monit.2015;21:882-889.

37. Wen S, Zhou W, Li CM, Hu J, Hu XM, Chen P, Shao GL, Guo WH. Ki-67 as a prognostic marker in early-stage non-small cell lung cancer in Asian patients: a metaanalysis of published studies involving 32 studies.BMC Cancer.2015;15:520.

38. Yamaguchi U, Hasegawa T, Sakurai S, Sakuma Y, Takazawa Y, Hishima T, Mitsuhashi T, Sekine S, Chuman $\mathrm{H}$, Shimoda $\mathrm{T}$. Interobserver variability in histologic recognition, interpretation of KIT immunostaining, and determining MIB-1 labeling indices in gastrointestinal stromal tumors and other spindle cell tumors of the gastrointestinal tract. Appl Immunohistochem Mol Morphol. 2006;14:46-51.

39. Ogino J, Asanuma H, Hatanaka Y, Matsuno Y, Gotoda H, Muraoka S, Tsuji T, Fukazawa Y, Yamashiro K, Kondo N, Iwaki H, Miyokawa N, Hasegawa T. Validity and reproducibility of $\mathrm{Ki}-67$ assessment in gastrointestinal stromal tumors and leiomyosarcomas. Pathol Int. 2013;63:102-107. 